\title{
Sustainable manufacturing of ultra-fine aluminium alloy 6101 wires using controlled high levels of mechanical strain and finite element modeling
}

\author{
Serafino Caruso $^{1}$ (D) $\cdot$ Luigino Filice $^{1}$ (D) \\ Received: 15 January 2021 / Accepted: 24 June 2021 / Published online: 19 July 2021 \\ (C) The Author(s) 2021
}

\begin{abstract}
The evolution of grain size and component mechanical behaviour are fundamental aspects to analyse and control when manufacturing processes are considered. In this context, severe plastic deformation (SPD) processes, in which a high shear strain is imposed on the material, are recognized as the main techniques to achieve microstructural changes and material strengthening by the recrystallization, attracting both academic and industrial investigation activities. At the same time, nowadays, sustainable manufacturing design is one of the main responsibilities of the researchers looking at UN2030 agenda and the modern industrial paradigms. In this paper a new severe SPD process is proposed with the aim to steer manufacturing to fourth industrial revolution using some of Industry 4.0 pillars. In particular, additive manufacturing (AM) and numerical simulations were setup as controlling and monitoring techniques in manufacturing process of wires. Strengthening effect (yield and ultimate tensile strength, plasticity and hardness) and microstructural evolution (continuous dynamic recrystallization -CDRX-) due to severe plastic deformation were experimentally analysed and numerically investigated by an innovative finite element (FE) model able to validate the effectiveness of a properly modified process for ultra-fine aluminium alloy AA6101 wires production designed with the aim to avoid any post manufacturing costly thermal treatment. The study provides an accurate experimental study and numerical prediction of the thermo-mechanical and microstructural phenomena that occur during an advanced large plastic deformation process; it shows how the combination of smart manufacturing and simulations control represents the key to renew the traditional manufacturing methods in the perspective of the Industry 4.0, connecting and integrating the manufacturing process for the industrial evolution in production.
\end{abstract}

Keywords Industry $4.0 \cdot$ Smart manufacturing $\cdot$ Additive manufacturing $\cdot$ Dynamic recrystallization $\cdot$ Grain size $\cdot$ Finite element modelling

\section{Introduction}

People feeling evolves over the time and some keywords becomes particularly important following social, scientific and cultural phenomena. Planet preservation is today no more a slogan and sustainability is one of the main performance

Serafino Caruso

serafino.caruso@unical.it

Luigino Filice

luigino.filice@unical.it

1 Department of Mechanical, Energy and Management Engineering, University of Calabria, Rende, CS 87036, Italy indicator of any human activity. Of course, industrial processes are part of the game. Industry 4.0 (I4.0), also named under the label of fourth industrial revolution, describes the convergence of several emerging concepts with digital technologies, devices and processes, reducing the human interference and reshaping manufacturing systems, economic and social life towards more sustainable practices [1-4]. The synergy between I4.0 and sustainable production can rewrite the current consumption and production patterns, playing a key role in increasing the prosperity of both economy and society. As it is well known, the United Nations (ONU) subscribed in 2015 an action program based on 17 Sustainable Development Goals (SDGs). Among these, both the consumption reducing and sustainable production represent Common Objectives (for Countries and individuals) in the fight against climate change 
and other world criticisms. The numerical simulation and the innovative process of additive manufacturing (AM) are two of the pillars characterizing I4.0 paradigm [5]. In fact, pillar integration leads to the smart manufacturing concept that represents the fourth industrial revolution core, improving manufacturing processes in terms of adaptability, flexibility, digital integration, efficient production, cost reduction and recyclability [6-9]. The industries which implement advanced manufacturing technologies such as AM instead of the conventional ones, promote the sustainable production enhancing smart manufacturing since it does not require complex tooling, reduces lead time and decreases material removal and the associate waste generation and management [10-13]. The manufacturing processes of ultra-fine aluminum-alloy wires can be carried out in the trending concepts of sustainability and I 4.0 by combining prediction capacity and flexibility which belong to numerical simulations and AM respectively. Focusing on manufacturing processes, several researches were proposed with the aim to adopt I4.0 concept in the companies. Herwan et al. [14] proposed and evaluated a feasible retrofitting method for old $\mathrm{CNC}$ turning with rotating tool holder: an artificial neural network was trained to predict tool flank wear allowing a smart worn tool changing. Backhaus and Nadarajah [15] presented a conceptual framework for Malaysian manufacturing sector, demonstrating how I4.0 may increase the competitiveness of the Malaysian manufacturing sector leading the Country to become a developed nation according to the eleventh Malaysia plan. Frank et al. [16] performed a survey in 92 manufacturing companies to study if manufacturing companies can be organized implementing I4.0 technologies. Their results showed that the implementation of big data, analytics and flexibility are the main challenges for companies to implement the fourth industrial revolution paradigm.

In manufacturing processes of ultra-fine aluminum-alloy wires, the enhancement of mechanical strength is an important aspect to make them suitable for a wide field of applications. According to Hall-Petch relation, the material flow stress behaviour is an inverse function of the square root of the grain size; for this reason, it is interesting to investigate the influence of plastic deformation on grain fragmentation and to understand how microstructure could improve the material properties during the process of fine wires. In this context, SPD processes are recognized as the main techniques to achieve microstructural changes and material strengthening by recrystallization. Many SPD methods were developed during the last years [17] but the concept of Equal Channel Angular Drawing (ECAD) [18] represents the most successful SPD technique for continuous production with homogeneous microstructure (Fig. 1). U. Chakkingal et al. [19] studied the mechanical and microstructural behaviour of pure aluminium 3004 when processed by ECAD method. Outcomes demonstrated an increase in material yield strength and hardness, highlighting that SPD technique is a suitable industrial approach to increase the mechanical properties of the material through a grain refinement. Zisman et al. [20] investigated the mechanical properties, the textures and microstructures of the sheet metals processed by a new simple method of ECAD, with adjustable die opening, comparing the obtained results with closely related process technique. Good enhancement in mechanical properties were found as a consequence of recrystallization phenomena. H. Zhao et al. [21] analysed the ECAD technology to manufacture CP-Ti rods and studied the effect of high drawing speed on microstructural changes using a $90^{\circ}$ die. Results showed the possibility to draw up to 12 passes without surface damage occurring in Equal Channel Angular Pressing (ECAP) and the evolution of deformation mode and microstructural changes.

Pérez et al. [22] studied the effect of two manufacturing ways and thermal treatments when ECAD process of is applied on 1370 aluminium alloy. The authors analysed the workpiece behaviour through two different procedures: A (no rotation of the workpiece between the steps) and B (a $90^{\circ}$ rotation of the workpiece at each step). Moreover, two different die channels were implemented for each procedure. The outcomes confirmed that grain refinement occurred, validating ECAD technique as an intermediate process during aluminium alloys wire drawing.

Chakkingal et al. [23] analysed three different routes of the ECAD process on pure commercial aluminium bars with extremely initial coarse grains of about $2000 \mu \mathrm{m}$ in size. The study showed a significant increase of the flow stress curve, with a corresponding decrease in ductility, resulting in microsized sub-grains with a shape variation from elongated to equiaxed. The authors showed the usefulness of ECAD method as a continuous industrial technique to manufacture bars with grain-refined microstructure and increased mechanical strength as compared to coarse-grained aluminium. Hence, with the aim (a) to extend the analysis of the effectiveness of the SPD technique in controlling the grain size changes and the material mechanical behaviour, (b) to analyse a new SPD approach to the conventional ECAD technique and (c) to give a further impulse to the introduction of I4.0 technologies in industrial production, the present work combines AM and FEM simulations for manufacturing of ultra-fine aluminiumalloy AA6101 wires by controlling mechanical strain with an innovative SPD manufacturing method.

The proposed severe plastic deformation process allows to obtain ultra-fine wires enhancing the material properties by microstructural evolution (grain refinement due to recrystallization) through an innovative AM device instead of the conventional post manufacturing thermal treatment in industrial furnaces, which requires a high amount of energy and time, or complex mechanical techniques such as the Equal Channel Angular Drawing (ECAD) process [20-22], Fig. 1. 


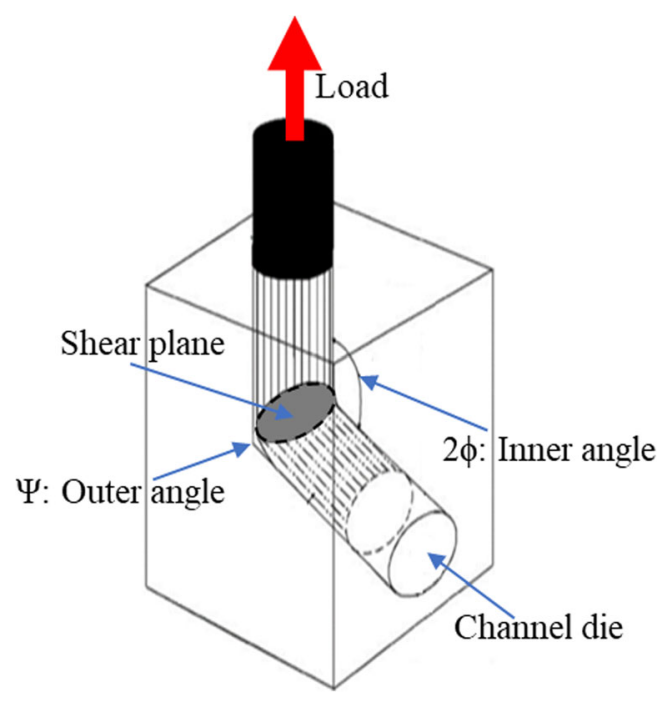

Fig. 1 Schematic illustration of the conventional ECAD-die

Furthermore, ECAD shows some limitations not only considering the chip usually generated for die manufacturing by the classic processes (turning or milling), which produce a scrap of material equal to about $55 \%$ of the workpiece, but also because ECAD die represents a rigid set-up that cannot be used for different wire diameters and does not allow to change the inner angle.

In the study here addressed, a FE model it used to predict the results of the new SPD process (stress, strain, grain size, hardness) and correct the deformation of the wire by rotating the developed AM device. In particular, an advanced flow stress empirical model, that includes the grain size variation, was developed to describe the material behaviour of aluminium alloy AA6101 during the deformation process, and two customized user sub-routine were implemented to predict the grain refinement and hardness variation. In this way it is possible to review the classical manufacturing methods (i.e. SPD by ECAD method in continuous production) in a new perspective, based on sustainability and computer integration, steering the industrial production to fourth industrial revolution.

\section{Experimental procedure}

Aluminium alloy AA6101 rods (Table 1) with an initial diameter of $9.50 \mathrm{~mm}$ were manufactured with a drawing speed of $25 \mathrm{~m} / \mathrm{sec}$ till to be reduced to a final diameter of $0.2 \mathrm{~mm}$, reaching a total section reduction of $99.95 \%$ and a total drawing strain of 7.72 .

Two manufacturing routes were performed and compared: Route A - the proposed innovative method in which the initial rods with a diameter of $9.50 \mathrm{~mm}$ were reduced to a final diameter of $0.2 \mathrm{~mm}$ by 15 initial cold-drawing passes, a subsequent SPD process and 23 final cold-drawing passes; Route B - the
Table 1 Material chemical composition

\begin{tabular}{lllllllll}
\hline $\mathrm{Al}$ & $\mathrm{Si}$ & $\mathrm{Fe}$ & $\mathrm{Cu}$ & $\mathrm{Mn}$ & $\mathrm{Mg}$ & $\mathrm{Cr}$ & $\mathrm{Ni}$ & $\mathrm{Zn}$ \\
\hline 97.6 & 0.49 & 0.50 & 0.10 & 0.03 & 0.40 & 0.03 & - & 0.10 \\
\hline
\end{tabular}

current technology in which the initial rods with a diameter of $9.50 \mathrm{~mm}$ were reduced to a final diameter of $0.2 \mathrm{~mm}$ by 38 cold-drawing passes. Both the compared routes are based on a total of 38 cold-drawing passes each one, but in the proposed innovative technique a SPD process is performed before the sixteenth cold-drawing pass, Fig. 2; Table 2.

In particular sample 1 is the initial rod with a diameter of $9.5 \mathrm{~mm}$, this is the same for both the two analysed manufacturing routes. Samples 2, 3 and 4 represent the state of the wire during the several passes characterizing the proposed innovative method (route A): sample 2 is the wire after the initial 15 cold-drawing passes, sample 3 is the wire after the SPD process and sample 4 is the wire after the final 23 cold-drawing passes. Sample 5 represents the state of the wire after the 38 cold-drawing passes characterizing the current technology (route B), Fig. 2.

In order to make comparable the results of the two investigated routes it was considered the same initial rod (sample 1) and the same number of cold-drawing passes ( 38 passes).

In the proposed innovative manufacturing method, a double reel AM device (Fig. 3) of stainless steel GP1 is interposed between two reduction sections in multipass cold-drawing (i.e. between the exit of the fifteenth drawing pass and the entrance of the sixteenth drawing pass) artificially causing a SPD on the wire. In this way, preserving the transversal dimension (wire diameter), a strengthening of material is observed as a consequence of recrystallization phenomena, obtaining the same effect of the ECAD process for continuous production of ultra-fine-grained materials with homogeneous microstructure.

Hence, the imposed strain is a direct function of the rotating angle $\theta$ (Fig. 3(b)), renewing the classic ECAD method with the possibility to tune the value of the imposed SPD on the wire by rotating the AM device (Fig. 3).

Uniaxial tensile tests of the aluminium rods, drawn wires and SPD processed wires were carried out at room temperature (Table 2). In particular, 15 experiments (three replications per sample) were performed and the average value was considered for each case allowing to make a comparison between the current technology of production (consisting of 38 colddrawing passes) and the proposed innovative SPD method (consisting of 38 cold-drawing passes in which a SPD process was performed before the sixteenth drawing pass), Fig. 4(a).

The tensile tests show how the imposed strain, for both drawing and the new SPD process, has a material strengthening effect on the manufactured wire. 

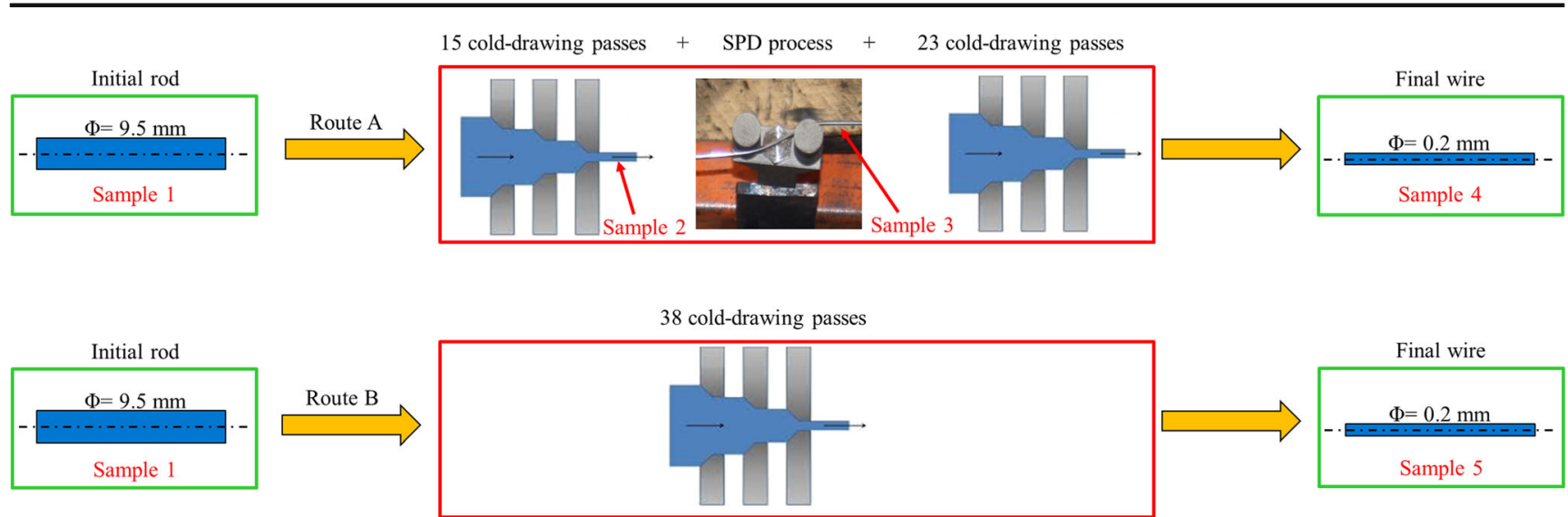

Fig. 2 Experimental investigated procedures

In fact, analysing the samples 1 and 4 , respectively the initial rod and the final wire of the proposed manufacturing method (route A), a total material strengthening of about 2.5 times was registered (Fig. 4(b)) with a reduction of the true strain from $\varepsilon=0.066$ to $\varepsilon=0.015$.

On the other hand, comparing the samples 1 and 5, respectively the initial rod and the final wire of the traditional colddrawn process (route B), the ultimate tensile strength increases of about 2 times with a plastic domain reduction of the $65 \%$.

Finally, by comparing the samples 4 and 5 , obtained respectively by imposing the new SPD method and the traditional cold-drawn process, an evident strengthening improvement over than $20 \%$ was observed, showing how the proposed innovative SPD technique induces the same effect usually produced by ECAD die, i.e. microstructural phenomena resulting in dislocation density and grain size evolution (i.e. grain refinement influencing the material strength for the HallPetch (H-P) effect $[19,24,25])$. Hence, the classic ECAD process is now renewed in the perspective of smart manufacturing and industry 4.0 because of the AM device and the possibility to regulate in real time the value of the mechanical strain imposed on the wire by rotating the double reel.

Afterward, specimen of each sample (Table 2) were mounted into a resin holder for the microstructural analysis of the transverse section. The metallographic preparation consisted of mechanical polishing and then etching by the use of Keller's reagent ( $92 \mathrm{ml}$ of distilled water, $6 \mathrm{ml}$ of nitric acid, $2 \mathrm{ml}$ of hydrochloric acid, $2 \mathrm{ml}$ hydrofluoric acid). The cross section of the samples has been studied under an optical microscope for microstructural analysis while the microhardness $\left(\mathrm{HV}_{0.01}\right)$ has been investigated by an instrumented micro-nano indenter.

In Fig. 5 the micrographs obtained by the optical microscopy analysis are reported. It is possible to observe that the grains of the initial rod (sample 1) are equiaxial and the average measured diameter was about $10.80 \mu \mathrm{m}$ (Fig. 5(a)). In Fig. 5(b) is shown the effect of the 15 cold-drawn passes on the microstructure (sample 2). The grains are smaller than the ones observed in the initial rod due to the significant plastic deformation accumulated in the material (average grain size equal to $3.10 \mu \mathrm{m}$ ). Subsequently, the rod has been undergone to a further SPD step (sample 3) as described in the experimental procedure. The aim of this step was to additionally improve the grain refinement and the results are quite encouraging as shown in Fig. 5(c) (average grain size equal to $2.10 \mu \mathrm{m}$ ). It is important to highlight that although the high intensity of the plastic deformation induced in the material, the microstructure morphology remains quite unchanged, indeed the grains mainly show an equiaxial shape.

Figure 5(d) represents the microstructure of the material at the end of the manufacturing process that include the presence of the SPD step (sample 4). The grain refinement phenomenon is quite significant as shown by the micrograph due to the
Table 2 Samples for uniaxial tensile tests

\begin{tabular}{lllll}
\hline Process procedure & Sample & Manufacturing step position & Diameter [mm] & Testing machine \\
\hline Route A & 1 & Initial rod & 9.5 & MTS Criterion Model 45 \\
& 2 & After 15 cold-drawn passes & 2.0 & MTS Criterion Model 45 \\
& 3 & After SPD process & 2.0 & MTS Criterion Model 45 \\
& 4 & After 23 cold-drawn passes & 0.2 & MTS Criterion Model 42 \\
Route B & 1 & Initial rod & 9.5 & MTS Criterion Model 45 \\
& 5 & After 38 cold-drawn passes & 0.2 & MTS Criterion Model 42 \\
\hline
\end{tabular}



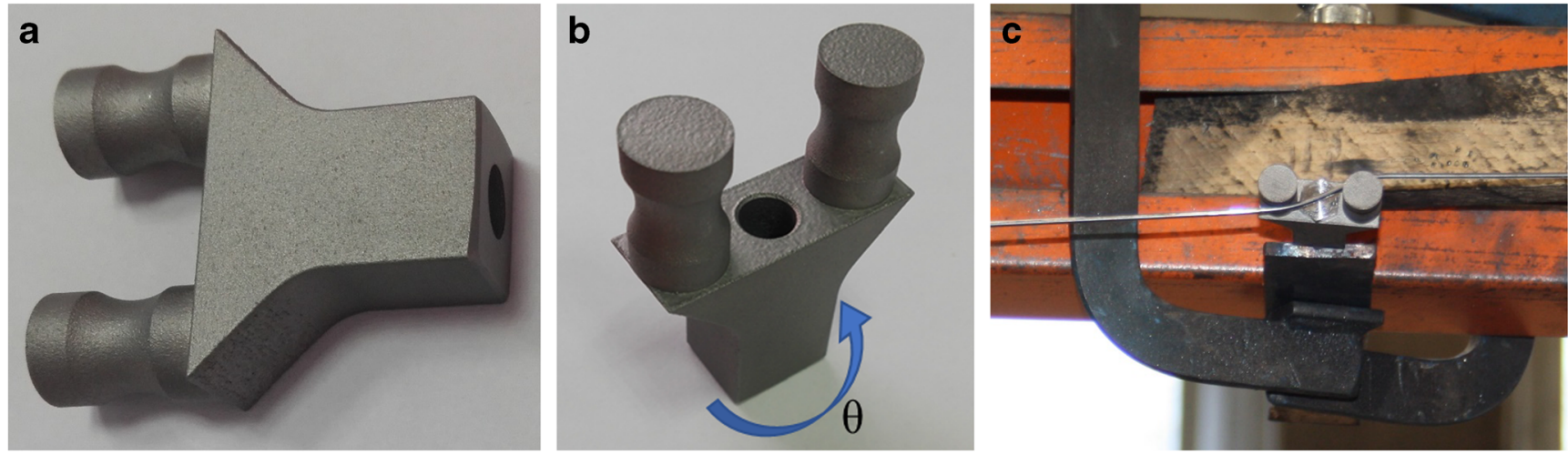

Fig. 3 (a)-(b) AM device, (c) experimental set-up

extra plastic deformation induced by the last 23 cold-drawn passes. The average value of the grain size measured is equal to $0.80 \mu \mathrm{m}$. This result is quite important especially if compared to the average grain size $(1.60 \mu \mathrm{m})$ measured on the material manufactured with 38 cold-drawn passes without including the SPD step (sample 5). The use of the SPD step enhanced the grain refinement during the further 23 colddrawn passes while operating directly with 38 cold-drawn passes allowed to achieve slightly coarser grains. It is important to highlight that although the grain size of the material undergone to the whole manufacturing process is slightly different, the morphology of the microstructure is quite comparable (Fig. 5(d), (e)). The recrystallization of the grains due to the intense plastic deformation is clearly confirmed by the metallographic analysis, although the use of the SPD step slightly enhances the grain refinement compared to the direct 38 cold-drawn passes.

The micro-hardness was measured on fifteen specimens (three units per sample, Table 2), ten indentations per specimen were carried out for a total of 150 tests and the average value was considered (Fig. 6).

Comparing the samples 1 and 4, characterized by the proposed manufacturing method (route A), the initial material hardness shows an increase of about 2 times. On the other hand, comparing the samples 1 and 5 , characterized by the traditional cold-drawn process (route B), the hardness evolution rises of about $60 \%$ only.

It is evident the role of the SPD, imposed by the double reel AM device, in influencing the final wire hardness.

However, the significant hardness increasing registered for both sample 4 and sample 5 is related to the inner mechanical aspect of cold-drawn process and the proposed innovative SPD method. In fact, both the analysed processes induce on the wire a large strain leading to grain size reduction for both dynamic recrystallization (DRX) phenomenon and strain hardening. Hence, as a consequence of the grain refinement (H-P effect), hardness increasing was observed for both the final manufactured wires samples 4 and 5. These results confirm, once again, the similitude between ECAD process and the developed SPD technique.

\section{Numerical model}

The commercial FE software SFTC DEFORM-3D ${ }^{\text {TM }}$ has been used to simulate the innovative SPD process of aluminium alloy AA6101 drawn-wire using coupled thermomechanical analysis with automatic remeshing. The workpiece was modelled as a plastic body meshed with 50,000 a

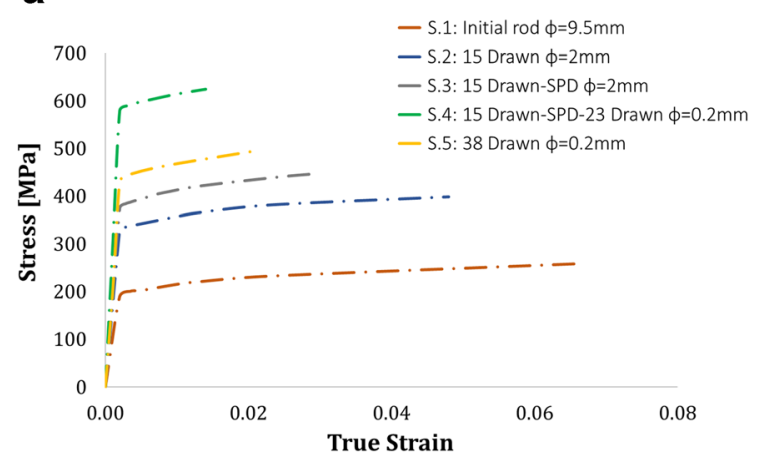

b

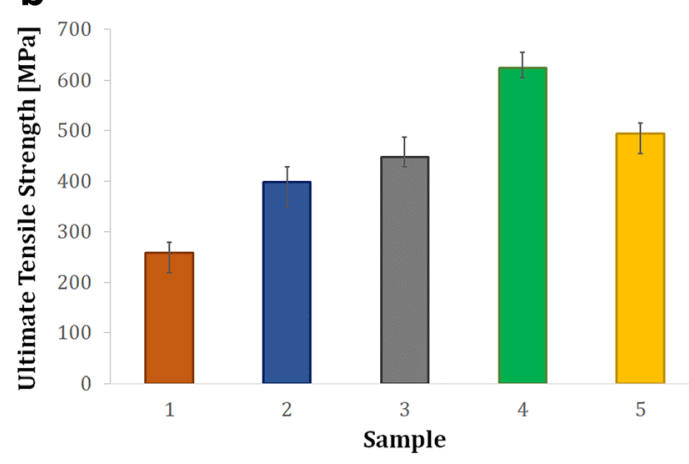

Fig. 4 a) True stress-strain curve, b) Ultimate tensile strength 


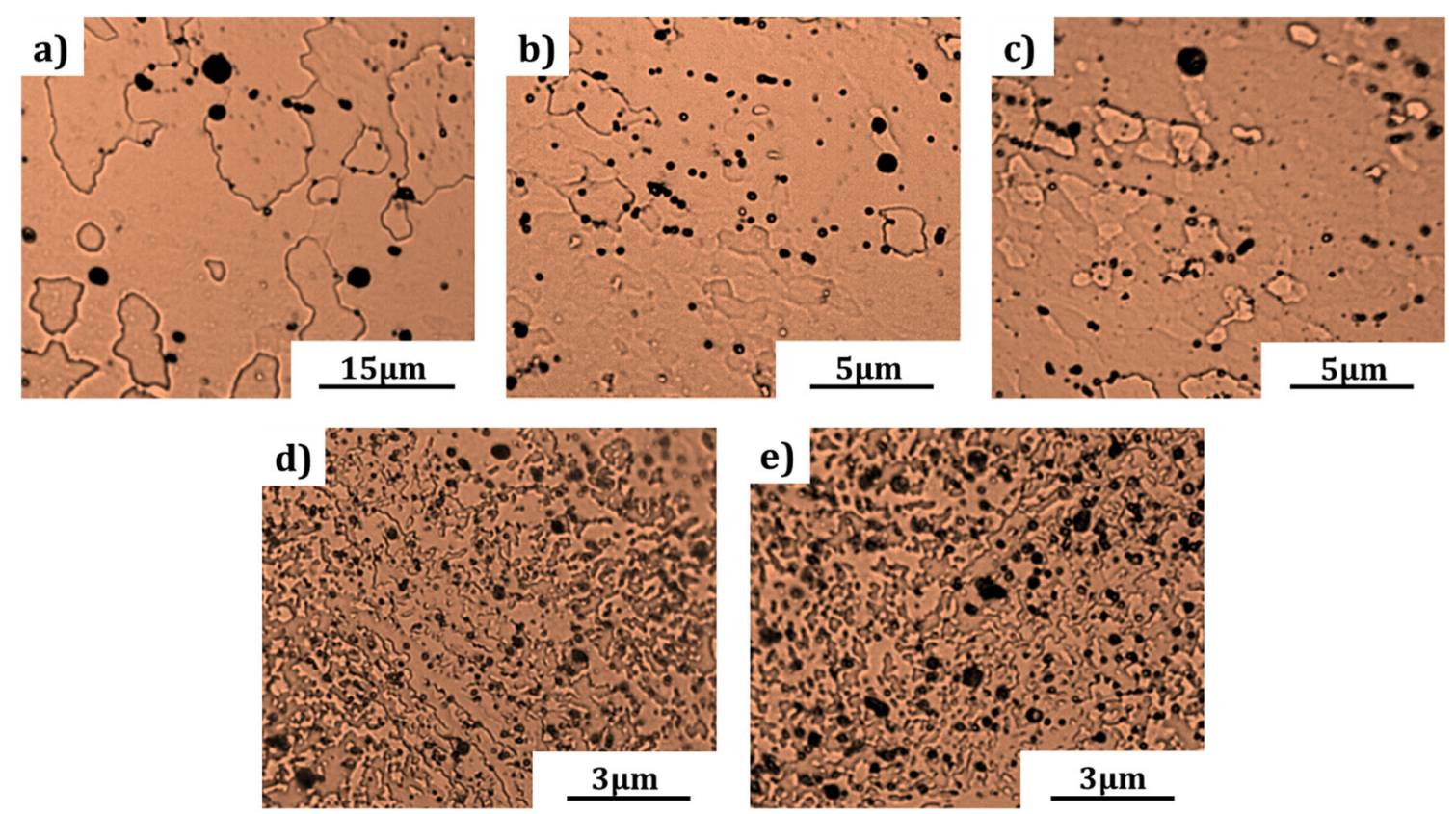

Fig. 5 Transverse section microstructure: (a) sample 1, (b) sample 2, (c) sample 3, (d) sample 4 and (e) sample 5

isoparametric tetrahedral elements, while for the die a rigid model with 32,000 elements was considered (Fig. 7).

A modified Johnson-Cook (J-C) flow stress model was developed to simulate the material behaviour under the proposed SPD condition. According to the original J-C model the flow stress is expressed as (Eq. 1).

$\sigma(\varepsilon, \dot{\varepsilon}, T)=\left(A+B \varepsilon^{n}\right)\left(1+\operatorname{Cln}\left(\frac{\dot{\varepsilon}}{\dot{\varepsilon_{0}}}\right)\right)\left(1-\left(\frac{T-T_{0}}{T_{m}-T_{0}}\right)^{m}\right)$

where $A$ is the yield stress at reference temperature and strain rate, $B$ and $\mathrm{n}$ respectively the coefficient and the exponent of strain hardening, $C$ the coefficient of strain rate hardening, $\varepsilon$ is the equivalent plastic strain, $\dot{\varepsilon}$ and $\dot{\varepsilon}_{0}$ are the plastic strain rate and the reference plastic strain rate respectively. $T_{0}$ is reference temperature, $T_{m}$ is the melting temperature and $m$ the thermal softening exponent.

To consider the influence of the grain refinement caused by DRX the constant $A$ (MPa) of the flow stress in Eq. 1 was

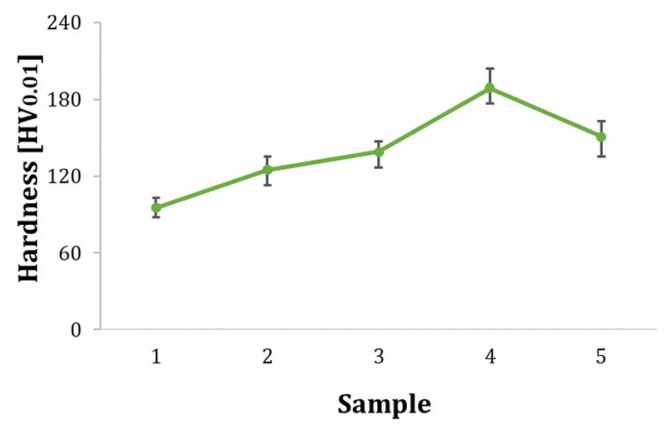

Fig. 6 Transverse section hardness measurements modified implementing the H-P equation (Eq. 2).

$A=\sigma_{y}=\sigma_{0}+\frac{k_{y}}{\sqrt{d}}$

Where $\sigma_{y}$ is the yield strength, $k_{y}$ is the strengthening coefficient, $\sigma_{0}$ is a material constant and $d$ is the average grain size.

Now the influence of the microstructural evolution (i.e. grain refinement), due to DRX, on the material strengthening is well described by the Hall-Petch (H-P) effect.

Hence, the thermo-mechanical behaviour of the aluminium alloy is numerically described by the new modified J-C law (Eq. 3).

$\sigma(\varepsilon, \dot{\varepsilon}, T, d)=\left(\left(\sigma_{0}+\frac{k_{y}}{\sqrt{d}}\right)+B \varepsilon^{n}\right)\left(1+C \ln \left(\frac{\dot{\varepsilon}}{\dot{\varepsilon_{0}}}\right)\right)\left(1-\left(\frac{T-T_{0}}{T_{m}-T_{0}}\right)^{m}\right)$

The values of the numerical constants $B, n, C$, and $m$, were determined by performing uniaxial tensile tests on the initial rods, at varying speeds and temperatures (Table 3), and adopting a regression analysis. For each tensile test condition

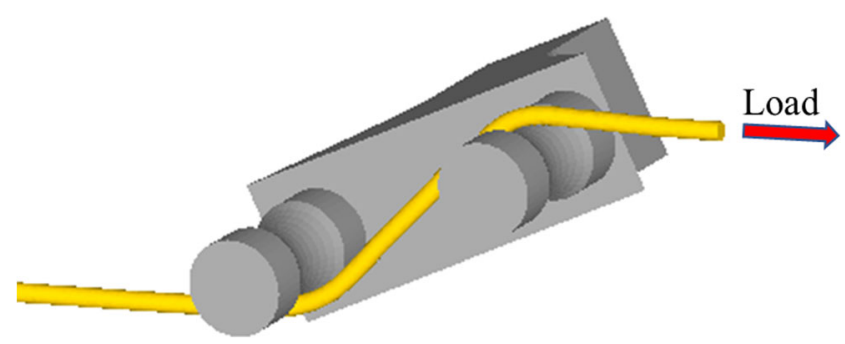

Fig. 7 FE model 
three experiments were performed, for a total of 27 experiments, and the average value was measured.

The numerical constants $\sigma_{0}$ and $k_{y}$ were determined by Eq. 2 through the previously measured values of the yield strength and the grain size of both initial aluminium rods (sample 1) and drawn wires (sample 5) manufactured by the classic process cold-drawn process.

All the constants characterizing the material behaviour (Eq. 3) are listed in Table 4.

In Fig. 8 the comparison between the numerical stressstrain data (Eq. 3) and the experiments is reported.

The physical events affecting the mechanical properties were predicted by implementing a customized user subroutine with a CDRX model for the grain refinement [26-28] and H-P equation for modelling the hardness evolution.

In particular, the CDRX represents the main physics metallurgical phenomena since aluminium alloy is a high stacking-fault energy material [29-31], therefore a continuum mechanical model to predict the grain size was implemented as in the follow:

$$
\begin{gathered}
d=d_{0}-\left(d_{0}-d_{f}\right)\left(1-\exp \left(-k_{x}<\varepsilon^{p} e_{\text {eff }}-\varepsilon^{p}{ }_{c}>^{C_{x}}\right)\right) \\
d_{f} \leq d \leq d_{0}
\end{gathered}
$$

where $d$ is the recrystallized grain size, $d_{0}$ the initial grain size, $d_{f}$ the saturation grain size, $k_{X}$ and $c_{X}$ are parameters describing the recrystallization evolution with increasing plastic deformation. The McCauley brackets $<>$ indicate that recrystallization phenomena will occur when the effective strain $\varepsilon^{p}$ eff will reach the threshold value $\varepsilon^{p}{ }_{c}$. The model developed by Y. Iwahashi et al. [32] was considered for the SPD process strain $\varepsilon^{\mathrm{p}}$ eff (Eq. 5).

$\varepsilon^{p}{ }_{\text {eff }}=\left(\frac{N_{\text {pass }}}{3^{0.5}}\right)\left(2 \cot \left(\frac{\Phi}{2}+\frac{\psi}{2}\right)+\psi \operatorname{cosec}\left(\frac{\Phi}{2}+\frac{\psi}{2}\right)\right)(5)$

where $\Phi$ and $\psi$ are the inner and outer angles (Fig. 1) and $N_{\text {pass }}$ is the number of the deformation passes.

While the parameters $k_{X}$ and $c_{X}$ and the critical strain leading to CDRX were set 3.8, 2 and 0.1 according to [29] respectively.

Finally, the hardness modification depending on the recrystallized grain size was calculated according to the H-P equation that considers hardness evolution as an inverse function of grain size (Eq. 6):

Table 3 Tensile test conditions
Table 4 Numerical material model parameters

\begin{tabular}{llllll}
\hline B & $\mathrm{n}$ & $\mathrm{C}$ & $\mathrm{m}$ & $\sigma_{0}$ & $\mathrm{k}_{\mathrm{y}}$ \\
\hline 340.12 & 0.43 & 0.01 & 1.12 & 40 & 493 \\
\hline
\end{tabular}

$H V=C_{0}+\frac{C_{1}}{\sqrt{d}}$

Where $C_{0}$ and $C_{l}$ are two material constants while $d$ represents the average grain size. The value of $C_{0}$ and $C_{l}$, were determined through the previously measured values of the material hardness and grain size of both initial aluminium rods (sample 1) and drawn wires (sample 5) manufactured by the classic process cold-drawn process and were equal to 60 and 115 , respectively.

\section{FE validation and results}

Numerical and experimental comparison of hardness variation and grain size evolution allowed to validate the developed FE model and the user subroutines.

Figure 9 reports the stable and uniform numerical results showing the effectiveness of the customized FEM in predicting the effects due to the innovative SPD process. In particular, the SPD induced by the AM device allows the effective strain $\varepsilon^{p}$ eff to overcome the threshold value $\varepsilon_{c}^{p}$, leading to the CDRX phenomena. Hence, a new grain size is evaluated leading to an evolution of the microstructure and influencing the material strength according to Eq. 3.

According to the experimental outcomes, the numerical results show that after the deformation, imposed by the double reel AM device, the CDRX events lead to the grain size evolution (i.e. grain refinement) which corresponds to a hardness increasing for the inverse function of H-P equation (Eq. 6). Thus, the obtained results confirm that the proposed SPD process causes severe structural changes resulting in mechanical properties modification, similar to the classic ECAD method, and the developed numerical model well predicts the phenomena taking place on micro and macro scale (Fig. 10).

Figure 11 shows the possibility to control the microstructure evolution changing the inner angle $\Phi$ of the wire by rotating the AM device.

The high deformation affects the microstructure of the aluminium initializing the grain refinement process, while high values of the $\Phi$ die angle results in low plastic strain reducing the effectiveness of grain size evolution. 
Fig. 8 Numerical stress-strain curves prediction

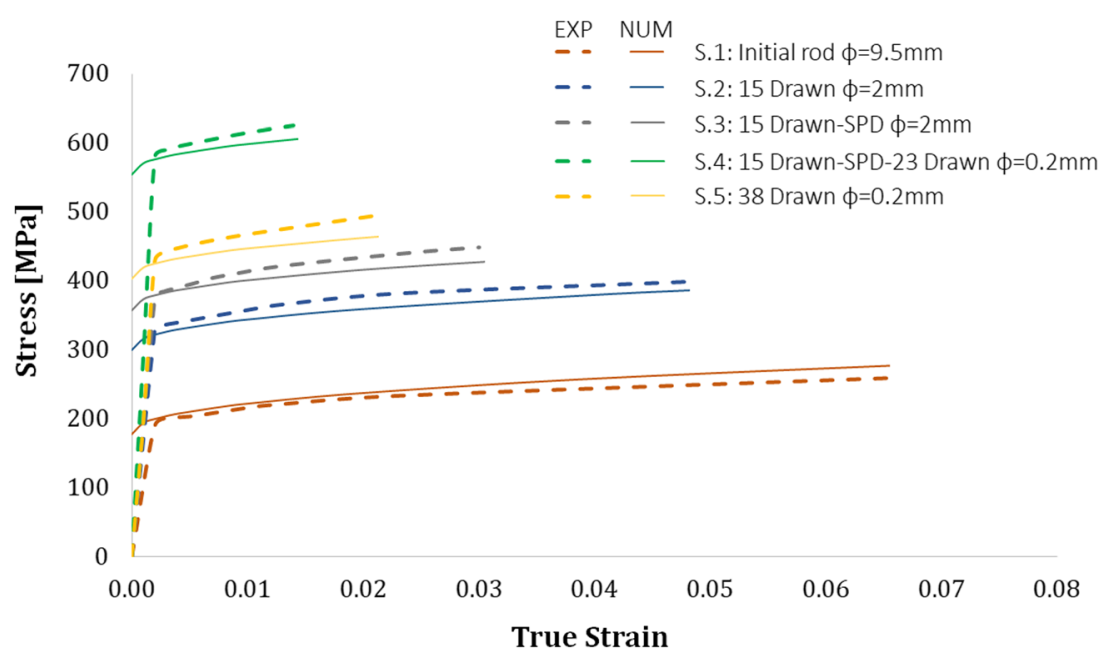

\section{Discussion and conclusions}

In the paper a new SPD process for ultra-fine aluminium alloy AA6101 wires production was proposed with the aim to increase process sustainability according to UN2030 agenda and basing on I4.0 pillar integration. In particular, by using $\mathrm{AM}$ and numerical simulations it was possible to review the traditional manufacturing process (SPD by ECAD method in continuous wires production) in a new perspective.

An innovative double reel AM device was developed and interposed among the classic multiple-pass cold-drawing with the possibility to tune the value of the imposed SPD on the wire.

The obtained experimental results (CDRX, grain refinement, hardness increasing and material strengthening).

i. validate the effectiveness of the proposed innovative SPD process in manufacturing ultra-fine aluminium wires with smaller diameters;

ii. show the possibility of the new deformation procedure to improve the flexibility of the manufacturing system because of the possibility to regulate and control in real time the value of the mechanical strain imposed on the wire looking towards I4.0;

iii. show the advantage of the double reel AM device avoiding the chip usually generated to manufacture the ECAD die by the classic processes (turning or milling) which produce a scrap of material equal to about $55 \%$ of the workpiece. Moreover, high lubrication efficiency and control are possible since the possibility to lead a delivery nozzle directly on the deformation zone;

iv. evidence the opportunity of the proposed innovative technique to manufacture wires of different diameters bypassing the limit of the ECAD die that represents a rigid set-up that cannot be used for different wire diameters and does not allow to change the inner angle;

v. show that the new interposed SPD method allows to enhance the material properties preventing the conventional post manufacturing thermal treatment in industrial furnaces which requires high amount of energy and time;

vi. candidate the proposed technique as a technological change able to reshape the conventional ECAD method.

According to the opportunity to build a digital twin, a FE model was developed implementing a continuum mechanical model and H-P relation for predicting grain size and hardness evolutions. A new modified J-C model was implemented considering the effect of grain size on the material behaviour during the SPD process. By this modification, the material flow stress is influenced by CDRX that significantly modifies the microstructure of the material (i.e. grain refinement) resulting in material strengthening for the H-P effect.
Fig. 9 Numerical prediction of (a) grain size and (b) hardness

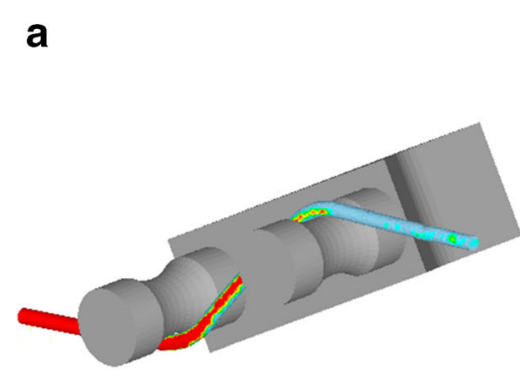

b

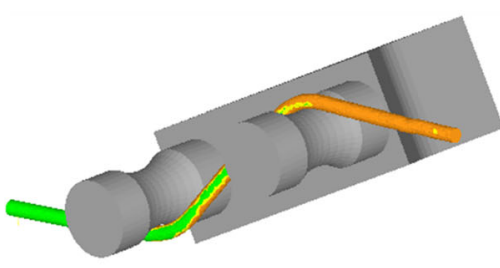

HARDNESS

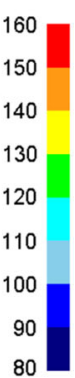


Sample 2

(After the 15th drawing pass)

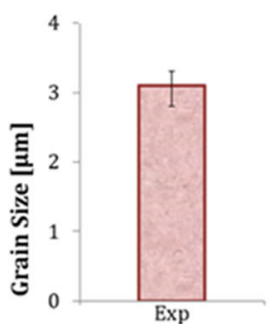

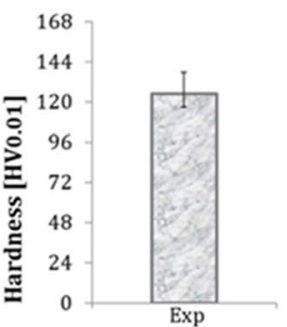

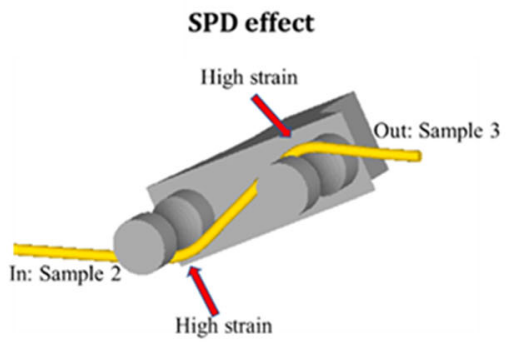

Sample 3

(After the SPD process)

Fig. 10 Numerical grain size and hardness prediction for the new SPD method
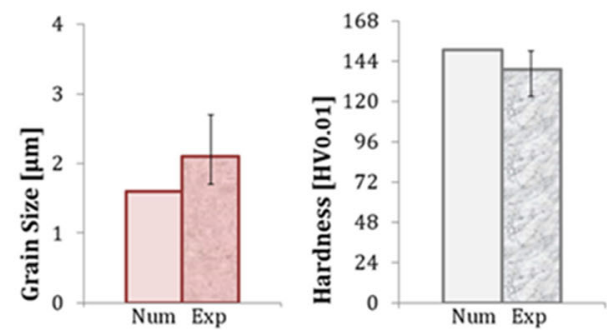

The numerical results were validated by comparison experimental tests demonstrating the effectiveness of the customized model and user subroutines to successfully predict the CDRX phenomena, taking place during the innovative SPD process, due to the high reached strains.

Thus, the proposed FE strategy can be used to properly simulate the material behaviour of aluminium alloy AA6101 during SPD process, providing accurate results since it was considered the influence of grain refinement on the material flow stress equation and on the microhardness variation.

Hence, the relation between microstructural changes and mechanical performance was experimentally and numerically analysed, showing how recrystallization, resulting in microstructural evolution, is an important aspect to control material's behaviour during the SPD processes.

In conclusion, the obtained numerical and experimental results confirm that the innovative SPD method causes severe structural changes, resulting in mechanical properties modification similar to the classic ECAD process, allowing industries to manufacture wires with a thinner section compared to the currently produced ones.

This aspect is of great importance especially for automotive industry attracted by finer aluminium wires to reduce vehicles weight especially for the new electric car development.

Furthermore, the whole innovative manufacturing system combines the AM with FEM to provide digital solutions, giving a solid contribute for manufacturing within I4.0 paradigm. The adoption of numerical simulation, to gather data and online analyse them, could provide useful information to monitor and control the manufacturing system in real time regulating, by an automatic actuator, the deformation imposed by the AM device on the manufactured wire.

Nomenclature A, yield stress; AM, additive manufacturing; $\mathrm{B}$, numerical constant; $\mathrm{C}$, numerical constant; $\mathrm{C}_{0}$, numerical constant; $\mathrm{C}_{1}$, numerical constant; $\mathrm{C}_{\mathrm{X}}$, numerical constant; $\mathrm{CNC}$, computer numerical control; ECAD, equal channel angular drawing; CDRX, continuous dynamic recrystallization; DRX, dynamic recrystallization; FE, finite element; FEM, finite element method; H-P, Hall-Petch; HV, Vickers hardness; I4.0, Industry 4.0 ; SPD, severe plastic deformation; $\mathrm{T}$, current temperature; $\mathrm{T}_{0}$, reference temperature; $\mathrm{T}_{\mathrm{m}}$, melting temperature; $\dot{\varepsilon}$, strain rate; $\dot{\varepsilon}_{0}$, reference strain rate; $\varepsilon$, effective strain; $\varepsilon^{\mathrm{p}}$ eff, effective plastic strain for grain size changes; $\varepsilon_{c}^{\mathrm{p}}$, critical plastic strain for grain size changes; $\Phi$, inner angle; $\Psi$, outer angle; $d$, average grain size; $d_{0}$, initial grain size; $d_{f}$, saturation grain size; $\mathrm{k}_{\mathrm{y}}$, numerical constant; $\mathrm{k}_{\mathrm{X}}$, numerical constant; $\sigma_{\mathrm{y}}$, yield strength; $\sigma_{0}$, numerical constant; $\mathrm{m}$, numerical constant; $\mathrm{n}$, numerical constant

Funding Open access funding provided by Università della Calabria within the CRUI-CARE Agreement.

Data availability Not applicable.

Code availability Commercial FE software SFTC DEFORM-3D ${ }^{\mathrm{TM}}$.

\section{Declarations}

Conflicts of interest/Competing interests Not applicable
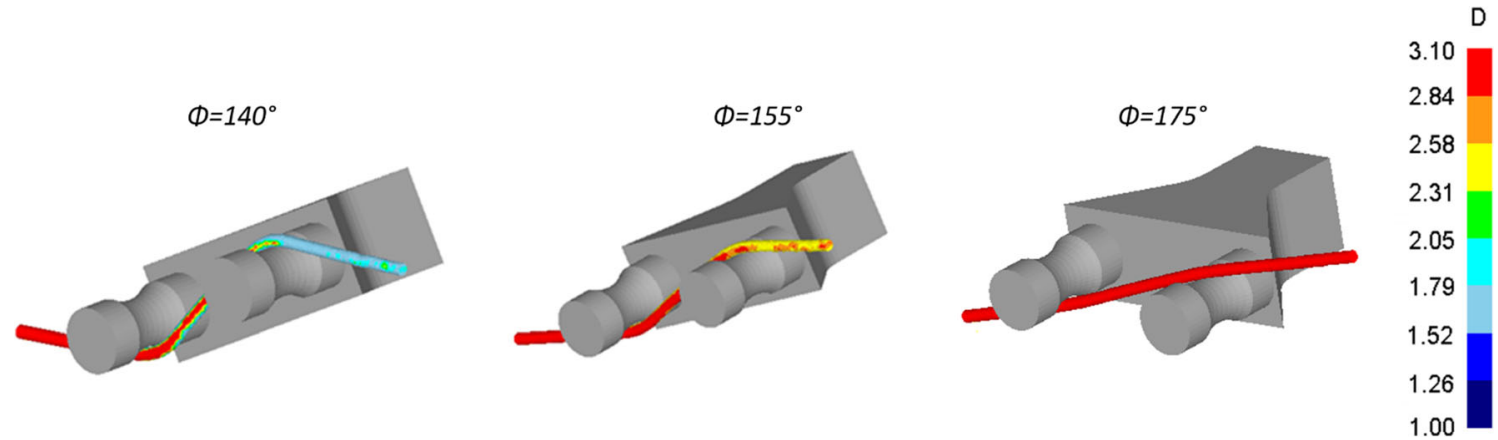

Fig. 11 Grain size evolution control on sample 3 
Open Access This article is licensed under a Creative Commons Attribution 4.0 International License, which permits use, sharing, adaptation, distribution and reproduction in any medium or format, as long as you give appropriate credit to the original author(s) and the source, provide a link to the Creative Commons licence, and indicate if changes were made. The images or other third party material in this article are included in the article's Creative Commons licence, unless indicated otherwise in a credit line to the material. If material is not included in the article's Creative Commons licence and your intended use is not permitted by statutory regulation or exceeds the permitted use, you will need to obtain permission directly from the copyright holder. To view a copy of this licence, visit http://creativecommons.org/licenses/by/4.0/.

\section{References}

1. Ahuett-Garza H, Kurfess T (2018) A brief discussion on the trends of habilitating technologies for Industry 4.0 and Smart manufacturing. Manuf Lett 15:60-63. https://doi.org/10.1016/j.mfglet.2018. 02.011

2. Dalenogare LS, Benitez GB, Ayala NF, Frank AG (2018) The expected contribution of Industry 4.0 technologies for industrial performance. Int J Prod Econ 204:383-394. https://doi.org/10. 1016/j.ijpe.2018.08.019

3. Lu Y (2017) Industry 4.0: A survey on technologies, applications and open research issues. J Indus Inf Integr 6:1-10. https://doi.org/ 10.1016/j.jii.2017.04.005

4. De Sousa Jabbour ABL, Jabbour CJC, Foropon C, Godinho Filho M (2018) When titans meet - Can industry 4.0 revolutionise the environmentally-sustainable manufacturing wave? The role of critical success factors. Technol Forecast Soc Change 132:18-25. https://doi.org/10.1016/j.techfore.2018.01.017

5. Raj A, Dwivedi G, Sharma A, De Sousa Jabbour ABL, Rajak S (2020) Barriers to the adoption of industry 4.0 technologies in the manufacturing sector: An inter-country comparative perspective. Int J Prod Econ 224:107546. https://doi.org/10.1016/j.ijpe.2019. 107546

6. Zawadzki P, Zywicki K (2016) Smart product design and production control for effective mass customization in the industry 4.0 concept. Manag Prod Eng Rev 7:105-112. https://doi.org/10. 1515/mper-2016-0030

7. Kusiak A (2019) Fundamentals of smart manufacturing: A multithread perspective. Annu Rev Control 47:214-220. https://doi.org/ 10.1016/j.arcontrol.2019.02.001

8. Park H-S, Febriani RA (2019) Modelling a Platform for Smart Manufacturing System. Procedia Manuf 38:1660-1667. https:// doi.org/10.1016/j.promfg.2020.01.118

9. Li Q, Tang Q, Chan I, Wei H, Pu Y, Jiang H, Li J, Zhou J (2018) Smart manufacturing standardization: Architectures, reference models and standards framework. Comput Ind 101:91-106. https://doi.org/10.1016/j.compind.2018.06.005

10. Ceruti A, Marzocca P, Liverani A, Bil C (2019) Maintenance in aeronautics in an industry 4.0 context: The role of augmented reality and additive manufacturing. J Comput Des Eng 6:516-526. https://doi.org/10.1016/j.jcde.2019.02.001

11. Rauch E, Unterhofer M, Dallasega P (2018) Industry sector analysis for the application of additive manufacturing in smart and distributed manufacturing systems. Manuf Lett 15B:126-131. https://doi. org/10.1016/j.mfglet.2017.12.011

12. Kumar A (2018) Methods and materials for smart manufacturing: additive manufacturing, Internet of Things, flexible sensors and soft robotics. Manuf Lett 15B:122-125. https://doi.org/10.1016/j. mfglet.2017.12.014
13. Shafranek RT, Cem Millik S, Smith PT, Lee C-U, Boydston AJ, Nelson A (2019) Stimuli-responsive materials in additive manufacturing. Prog Polym Scy 93:36-67. https://doi.org/10. 1016/j.progpolymsci.2019.03.002

14. Herwan J, Kano S, Ryabov O, Sawada H, Kasashima N, Misaka T (2019) Retrofitting old CNC turning with an accelerometer at a remote location towards Industry 4.0. Manuf Lett 21:56-59. https://doi.org/10.1016/j.mfglet.2019.08.001

15. Backhaus SKH, Nadarajah D (2019) Investigating the relationship between industry 4.0 and productivity: a conceptual framework for Malaysian manufacturing firms. Procedia Comput Sci 161:696706. https://doi.org/10.1016/j.procs.2019.11.173

16. Frank AG, Dalenogare LS, Ayala NF (2019) Industry 4.0 technologies: Implementation patterns in manufacturing companies. Int $\mathrm{J}$ Prod Econ 210:15-26. https://doi.org/10.1016/j.ijpe.2019.01.004

17. Faraji G, Torabzadeh H (2019) An overview on the continuous severe plastic deformation methods. Mater Trans 60(7):13161330. https://doi.org/10.2320/matertrans.MF201905

18. Suriadi AB, Thomson PF (1997) Control of deformation history for homogenizing and optimizing mechanical properties of metals. Proceedings of Australiasia-Pacific Forum on Intelligent Processing \& Manufacturing of Materials. IPMM:920-926

19. Chakkingal U, Suriadi AB, Thomson PF (1998) Microstructure development during equal channel angular drawing of $\mathrm{Al}$ at room temperature. Scr Mater 39:677-684. https://doi.org/10.1016/ S1359-6462(98)00234-6

20. Zisman AA, Rybin VV, Van Boxel S, Seefeldt M, Verlinden B (2006) Equal channel angular drawing of aluminium sheet. Mater Sci Eng A 427(1-2):123-129. https://doi.org/10.1016/j.msea.2006. 04.007

21. Zhao H, Ren Y, Yang B, Qin G (2019) Microstructural evolution of equal channel angular drawn purity titanium at room temperature. $\mathrm{J}$ Alloys Compd 811:152002. https://doi.org/10.1016/j.jallcom.2019. 152002

22. Luis Pérez CJ, Berlanga C, Pérez-Ilzarbe J (2003) Processing of aluminium alloys by equal channel angular drawing at room temperature. J Mater Process Technol 143-144:105-111. https://doi. org/10.1016/S0924-0136(03)00329-7

23. Chakkingal U, Suriadi AB, Thomson PF (1999) The development of microstructure and the influence of processing route during equal channel angular drawing of pure aluminum. Mater Sci Eng A 266(1-2):241-249. https://doi.org/10.1016/S0921-5093(98) $01129-0$

24. Hall EO (1951) The deformation and ageing of mild steel: III discussion of results. Proc Phys Soc B 64:747-753. https://doi.org/10. 1088/0370-1301/64/9/303

25. Petch NJ (1953) The cleavage strength of polycrystals. J Iron Steel Inst 174:25-28

26. Hallberg H (2011) Approaches to modeling of recrystallization. Metals 1:16-48. https://doi.org/10.3390/met1010016

27. Sakai T, Jonas JJ (1984) Overview no. 35 Dynamic recrystallization: Mechanical and microstructural considerations. Acta Metall 32:189-209. https://doi.org/10.1016/0001-6160(84)90049-X

28. Jonas JJ (1994) Dynamic recrystallization - scientific curiosity or industrial tool? Mater Sci Eng A 184:155-165. https://doi.org/10. 1016/0921-5093(94)91028-6

29. Hallberg H, Wallin M, Ristinmaa M (2010) Modeling of continuous dynamic recrystallization in commercial-purity aluminum. Mater Sci Eng A 527:1126-1134. https://doi.org/10.1016/j.msea. 2009.09.043

30. Sakai T, Miura H, Yang X (2009) Ultrafine grain formation in face centered cubic metals during severe plastic deformation. Mater Sci Eng A 499:2-6. https://doi.org/10.1016/j.msea.2007.11.098

31. Yamagata H, Ohuchida Y, Saito N, Otsuka M (2001) Nucleation of new grains during discontinuous dynamic recrystallization of 
99.998 mass\% Aluminum at $453 \mathrm{~K}$. Scr Mater 45:1055-1061. https://doi.org/10.1016/S1359-6462(01)01139-3

32. Iwahashi Y, Wang J, Horita Z, Nemoto M, Langdon TG (1996)

Principle of equal-channel angular pressing for the processing of ultra-fine grained materials. Scr Mater 35:143-156. https://doi.org/ 10.1016/1359-6462(96)00107-8
Publisher's Note Springer Nature remains neutral with regard to jurisdictional claims in published maps and institutional affiliations. 